\title{
Prognostic variables associated with improved outcomes in patients with stage III NSCLC treated with chemoradiation followed by consolidation Pembrolizumab: a subset analysis of a phase II study from the Hoosier Cancer Research Network LUN 14-179
}

\author{
Bilal Anouti ${ }^{1}$, Sandra Althouse ${ }^{2}$, Greg Durm ${ }^{3}$, Nasser Hanna ${ }^{3 *}$ \\ ${ }^{1}$ Indiana University Department of Internal Medicine, 1120 W Michigan St, Indianapolis, IN 46202, USA; \\ ${ }^{2}$ Indiana University Department of Biostatistics, 410 W. 10th Street HITS 3000, Indianapolis, IN 46202, USA; \\ ${ }^{3}$ Indiana University Simon Cancer Center, 535 Barnhill Dr., Indianapolis, IN 46202, USA
}

*Corresponding author will be Dr. Nasser Hanna (nhanna@iu.edu)

This is the author's manuscript of the article published in final edited form as:

Anouti, B., Althouse, S., Durm, G., \& Hanna, N. (2019). Prognostic variables associated with improved outcomes in patients with stage III NSCLC treated with chemoradiation followed by consolidation Pembrolizumab: A subset analysis of a phase II study from the Hoosier Cancer Research Network LUN 14-179. Clinical Lung Cancer, 0(0). https://doi.org/10.1016/j.cllc.2019.06.009 


\begin{abstract}
:

\section{Introduction}

HCRN LUN 14-179 is a phase II trial of consolidation pembrolizumab following concurrent chemoradiation for the treatment of patients with stage III NSCLC. Time to metastatic disease, progression free survival and overall survival appear superior to historical controls of chemoradiation alone. Unfortunately, not all patients benefit from consolidation immunotherapy. We performed a univariate analysis evaluating variables associated with PFS, metastatic disease, and OS.
\end{abstract}

\title{
Methods
}

We conducted a retrospective analysis from patients enrolled on HCRN LUN14-179. Data collected included age, sex, stage, smoking status, PD-L1 status, $\geq \mathrm{G} 2$ vs $\leq \mathrm{G} 1$ adverse event, $\leq \mathrm{G} 2$ vs. $\geq \mathrm{G} 3$ pneumonitis, duration of pembrolizumab ( $<4$ vs. $\geq 4$ cycles), chemotherapy regimen, PS 0 vs 1, time to start pembrolizumab (4-6 vs. 6-8 weeks from radiation), $\mathrm{V}_{20}(<20 \%$ vs. $\geq 20 \%$ ). Univariable Cox regression was performed to determine the variables associated with 3 endpoints: TMDD; PFS; and OS.

\section{Results}

From April 2015 to December 2016, 93 patients were enrolled and 92 were included in the efficacy analysis (1 patient was ineligible). For TMDD, improved outcomes may be associated $(\mathrm{p}<0.1)$ with stage IIIA, non-squamous cell, $\geq 4$ cycles of pembrolizumab, and $\mathrm{V}_{20}<$ $20 \%$. For PFS, improved outcomes $(p<0.1)$ may be seen for $\geq 4$ cycles of pembrolizumab, and $\mathrm{V}_{20}<20 \%$. For OS, improved outcomes $(\mathrm{p}<0.1)$ may be seen for non-squamous histology, $\geq 4$ cycles of pembrolizumab.

\section{Conclusion}

Non-squamous NSCLC, longer duration of pembrolizumab, and $\mathrm{V}_{20}<20 \%$ may be associated with prolonged time to metastatic disease or death, PFS, and OS for patients with stage III NSCLC treated with chemoradiation followed by pembrolizumab.

\section{Keywords:}

Immunotherapy, Non-small cell lung cancer, Adjuvant therapy, Prognosis. 


\section{Introduction:}

Over the last 20 years, the 5 year survival rate for patients with stage IIIA and IIIB NSCLC has been $10-15 \%$ and $3-7 \%$, respectively ${ }^{1}$. The standard of care for these patients during this period remained concurrent chemotherapy and radiation therapy ${ }^{2-4}$. This standard has recently changed, based upon the results from the randomized, phase III PACIFIC trial. In this study, patients with stage III NSCLC were treated with a variety of chemotherapy regimens concomitantly with radiation therapy and subsequently randomized in a 2:1 fashion to receive either durvalumab, a PD-L1 inhibitor, or placebo for up to 1 year. Median progression-free survival for those receiving durvalumab was 16.8 compared with 5.6 months for placebo. Overall survival was also improved for those receiving durvalumab with a 24-month overall survival rate of $66.3 \%$ compared with $55.6 \%$ in the placebo group ${ }^{5}$. A phase II study from the Hoosier Cancer Research Network (HCRN LUN 14-179) evaluated the role of consolidation pembrolizumab after chemoradiation in patients with stage III NSCLC. This study recruited patient from 14 sites in the U.S. Results from this study indicated efficacy outcomes [progression free-survival (PFS), time to metastatic disease or death (TMDD), and overall survival (OS)] similar to those achieved with durvalumab in the PACIFIC trial with median TMDD of 22.4 months and a median PFS of 17 months in a similar study population.

Prognostic variables associated with improved outcomes in patients with stage III NSCLC treated with chemoradiation are well characterized. Performance status 0-1, absence of weight loss in the 3 months preceding the diagnosis of lung cancer, stage IIIA (compared with IIIB) disease, and volume of lung receiving at least $20 \mathrm{~Gy}$ of radiation (V20) $<20 \%$ are associated with improved outcomes ${ }^{6-8}$. However, prognostic variables associated with improved efficacy from consolidation immunotherapy after chemoradiation therapy have not been defined. The anti-cancer mechanisms of checkpoint inhibitors is substantially different than conventional chemotherapy. Furthermore, checkpoint inhibitors are associated with a vastly different side effect profile compared with conventional chemotherapy. We, therefore, performed this retrospective subset analysis to evaluate potential prognostic variables associated with improvements in TMDD, PFS, and OS in patients with stage III NSCLC treated with chemoradiation followed by pembrolizumab from the HCRN LUN 14-179 clinical trial. 


\section{Methods:}

\section{Study population}

We conducted a retrospective analysis from patients enrolled on HCRN LUN 14-179. This was a single arm, phase II trial of concurrent chemoradiation followed by consolidation pembrolizumab $200 \mathrm{mg}$ IV every 3 weeks until disease progression, unacceptable toxicity, or up to 1 year of therapy was completed. Patients were permitted to receive carboplatin plus paclitaxel, cisplatin plus etoposide, or cisplatin plus pemetrexed (non-squamous cell only) given concurrently with 59.4-66.6 Gy XRT. Patients were also permitted up to 2 cycles of consolidation chemotherapy. Patients with non-progression of disease were then enrolled onto the clinical trial. Eligible patients had a PS of 0-1, stage IIIA or IIIB squamous or non-squamous NSCLC. Patients with contraindications to checkpoint inhibitors were excluded, including a history of non-infectious pneumonitis or interstitial lung disease. Patients were not excluded based upon pulmonary function, V20 or weight loss. The primary objective of the overall study was to determine if consolidation pembrolizumab following concurrent chemoradiation improves time to death or metastatic disease in inoperable stage III NSCLC patients. The efficacy and safety results of the overall study population have been reported ${ }^{9}$. The primary objective of this subset analysis was to determine prognostic variables associated with TMDD, PFS and OS.

\section{Prognostic variables}

Prognostic variables considered for this analysis included age, sex, stage of NSCLC (IIIA vs. IIIB), histology (squamous vs. non-squamous), smoking status (current vs. former vs. never smoker), PD-L1 status ( $\geq 1 \%$ vs. $<1 \%)$, any adverse event grade $((\leq \mathrm{G} 2$ vs. $\geq \mathrm{G} 3)$, pneumonitis ( $\leqq \mathrm{G} 2$ vs. $\geqq \mathrm{G} 3$ ), duration of treatment with pembrolizumab ( $<4$ vs. $\geqq 4$ cycles), chemotherapy regimen (carboplatin/paclitaxel vs. cisplatin/etoposide), ECOG performance status (0 vs. 1), interval between completion of radiation to start of pembrolizumab (4-6 weeks vs. 6-8 weeks) and volume of lung receiving at least 20 Gy of radiation (V20) ( $\leq 20 \%$ vs. $>20 \%)$. PD-L1 testing was performed using modified proportion score (MPS). This scoring system includes both PD-L1 positive mononuclear inflammatory cells (MIC), including macrophages and lymphocytes, and tumor cells. It also evaluates MICs within the tumor-associated stroma, though this is not factored into the percent MPS score. 


\section{Statistical analysis}

Data analysis was conducted using SAS software version 9.4 (SAS Institute Inc., Cary, NC). A p-value <.05 denoted statistical significance for all tests. Basic comparisons were made using Chi-Square Tests. Univariable Cox regression was performed to determine the variables associated with 3 endpoints: TMDD, PFS and OS. Variables found to have a $\mathrm{P}<0.1$ on univariable Cox regression analysis were included in a multivariable Cox regression model. Due to a small sample size $(n=92)$, we chose $p<0.1$ as the cutoff in the univariable regression for inclusion into the multivariable regression model, to allow us to still develop hypothesisgenerating prognostic variables to be studied in larger trials in the future..

\section{Results:}

From April 2015 to December 2016, 93 patients were enrolled and 92 were included in the efficacy analysis (1 patient was ineligible). The median follow-up was 30.5 months with a minimum follow-up of 26 months for patients who are alive. Patient and disease characteristics are summarized in Table 1.

For time to metastatic disease or death (TMDD), improved outcomes $(\mathrm{p}<0.1)$ were associated with stage IIIA ( $\mathrm{p}=0.0922)$, non-squamous cell $(\mathrm{p}=0.0999), \geq 4$ cycles of pembrolizumab $(\mathrm{p}<0.001)$, and $\mathrm{V} 20 \leq 20 \%(\mathrm{p}=0.0716)$ according to the Univariable Cox regression model. A multivariable model was run with those variables and Stage IIIA (HR=2.9, $\mathrm{p}=0.02)$ and $\geq 4$ cycles of pembrolizumab $(\mathrm{HR}=9.1, \mathrm{p}<0.001)$ remained significant. On the other hand, smoking status was not associated with a difference in TMDD $(\mathrm{p}=0.7204)$ on univariable Cox regression model. PDL-1 status was also not associated with TMDD ( $\mathrm{p}=0.3505$ ) (Table 3 ).

For PFS, improved outcomes $(\mathrm{p}<0.1)$ may be seen for $\geq 4$ cycles of pembrolizumab $(\mathrm{p}<0.001)$, and $\mathrm{V} 20 \leq 20 \%(\mathrm{p}=0.0630)$ according to the Univariable Cox regression model. A multivariable model was run with those variables and $\geq 4$ cycles of pembrolizumab $(\mathrm{HR}=3.9$, $\mathrm{p}<0.001)$ remained significant. Smoking status $(\mathrm{p}=0.9679)$, PDL-1 status $(\mathrm{p}=0.3261)$, and stage IIIA vs. IIIB ( $\mathrm{p}=0.1444)$ were not associated with PFS. (Table 4).

For OS, improved outcomes $(\mathrm{p}<0.1)$ may be seen for non-squamous histology $(\mathrm{p}=0.0829)$, and $\geq 4$ cycles of pembrolizumab $(\mathrm{p}<0.001)$ according to the univariable Cox regression model. A multivariable model was run with those variables and $\geq 4$ cycles of 
pembrolizumab $(\mathrm{HR}=4.9, \mathrm{p}<0.001)$ remained significant. Smoking status $(\mathrm{p}=0.6043)$, PDL-1 status $(\mathrm{p}=0.1901)$ and stage of disease $(\mathrm{p}=0.1588)$ were not prognostic for OS (Table 5).

Table 1: Baseline characteristics of study population $(\mathrm{N}=92)$

\begin{tabular}{|c|c|}
\hline \multicolumn{1}{|c|}{ Characteristics } & Statistics \\
\hline Age (years), mean (std) & $64(8.6)$ \\
\hline Gender, n (\%) Male & $59(64)$ \\
\hline \multicolumn{1}{|c|}{ Female } & $33(36)$ \\
\hline Stage, n (\%) IIIA & \\
\hline IIIB & $55(60)$ \\
\hline Histology of NSCLC, n (\%) & $37(40)$ \\
\hline Non-squamous & $51(55)$ \\
\hline Squamous & $41(45)$ \\
\hline \begin{tabular}{r|r|} 
Distant metastasis or death on follow-up*, n \\
$(\%)$
\end{tabular} & $34(37)$ \\
\hline Present & $57(63)$ \\
\hline Not present & \\
\hline
\end{tabular}

*One patient did not have an evaluable response for distant metastasis or death

Table 2: Basic comparisons of outcomes

\begin{tabular}{|l|l|l|l|}
\hline \multicolumn{1}{|c|}{ Variable } & \multicolumn{1}{|c|}{ TMDD } & \multicolumn{1}{c|}{ OS } \\
\hline IIIA (n=55) & $69 \% \quad \mathrm{p}=0.12$ & $56 \% \quad \mathrm{p}=0.21$ & $75 \% \mathrm{p}=0.13$ \\
IIIB (n=37) & $51 \%$ & $41 \% \quad$ & $59 \%$ \\
\hline Non-SCCA (n=51) & $69 \% \quad \mathrm{p}=0.11$ & $55 \% \quad \mathrm{p}=0.21$ & $75 \% \quad \mathrm{p}=0.16$ \\
SCCA (n=41) & $54 \% \quad$ & $44 \% \quad$ & $61 \%$ \\
\hline PD-L1 [-] (n=11) & $82 \% \quad \mathrm{p}=0.13$ & $64 \% \quad \mathrm{p}=0.19$ & $91 \% \quad \mathrm{p}=0.07$ \\
PD-L1 [+] (n=42) & $57 \%$ & $40 \%$ & $62 \%$ \\
\hline
\end{tabular}




\begin{tabular}{|c|c|c|c|}
\hline $\begin{array}{l}\geq 4 \text { pembro }(n=77) \\
<4 \text { pembro }(n=15)\end{array}$ & $\begin{array}{ll}68 \% & p=0.01 \\
33 \% & \end{array}$ & $\begin{array}{l}55 \% \mathrm{p}=0.04 \\
27 \%\end{array}$ & $\begin{array}{ll}75 \% & p=0.001 \\
33 \% & \end{array}$ \\
\hline $\begin{array}{l}V_{20} \leq 20 \%(n=19) \\
V_{20}>20 \%(n=59)\end{array}$ & $\begin{array}{ll}79 \% & \mathrm{p}=0.07 \\
54 \% & \end{array}$ & $\begin{array}{ll}63 \% & \mathrm{p}=0.08 \\
39 \% & \end{array}$ & $\begin{array}{l}79 \% \quad \mathrm{p}=0.15 \\
61 \%\end{array}$ \\
\hline $\begin{array}{l}G \leq 2 \text { pneumonitis }(n=87) \\
G \geq 3 \text { pneumonitis }(n=5)\end{array}$ & $\begin{array}{ll}63 \% & p=0.28 \\
40 \% & \end{array}$ & $\begin{array}{ll}51 \% & \mathrm{p}=0.61 \\
40 \% & \end{array}$ & $\begin{array}{l}70 \% \quad \mathrm{p}=0.16 \\
40 \%\end{array}$ \\
\hline $\begin{array}{l}\text { Female }(n=33) \\
\text { Male }(n=59)\end{array}$ & $\begin{array}{ll}67 \% & p=0.37 \\
59 \% & \end{array}$ & $\begin{array}{l}67 \% \mathrm{p}=0.11 \\
59 \%\end{array}$ & $\begin{array}{l}73 \% \quad p=0.51 \\
66 \%\end{array}$ \\
\hline $\begin{array}{l}<65 \text { years old }(n=43) \\
\geq 65 \text { years old }(n=49)\end{array}$ & $\begin{array}{ll}56 \% & p=0.32 \\
67 \% & \end{array}$ & $\begin{array}{l}49 \% \mathrm{p}=0.99 \\
51 \%\end{array}$ & $\begin{array}{l}65 \% \mathrm{p}=0.52 \\
71 \%\end{array}$ \\
\hline $\begin{array}{l}\text { Current Smoker }(n=16) \\
\text { Former Smoker }(n=71) \\
\text { Never Smoker }(n=5)\end{array}$ & $\begin{array}{l}50 \% \quad \mathrm{p}=0.42 \\
66 \% \\
40 \%\end{array}$ & $\begin{array}{l}50 \% \\
51 \% \\
40 \%\end{array}$ & $\begin{array}{l}56 \% \mathrm{p}=0.44 \\
72 \% \\
60 \%\end{array}$ \\
\hline $\begin{array}{l}\text { Any AE Grade } \leq 2(n=46) \\
\text { Any AE Grade } \geq 3(n=46)\end{array}$ & $\begin{array}{ll}70 \% & \mathrm{p}=0.17 \\
54 \% & \end{array}$ & $\begin{array}{l}56 \% \quad \mathrm{p}=0.29 \\
43 \%\end{array}$ & $\begin{array}{l}76 \% \quad p=0.12 \\
61 \%\end{array}$ \\
\hline $\begin{array}{l}\text { Carboplatin/Paclitaxel }(n=66) \\
\text { Cisplatin/Etoposide }(n=24)\end{array}$ & $\begin{array}{l}59 \% \quad \mathrm{p}=0.57 \\
67 \%\end{array}$ & $\begin{array}{l}44 \% \mathrm{p}=0.15 \\
63 \%\end{array}$ & $\begin{array}{l}65 \% \mathrm{p}=0.38 \\
75 \%\end{array}$ \\
\hline $\begin{array}{l}\text { Rad Interval 4-6 weeks }(n=17) \\
\text { Rad Interval 6-8 weeks }(n=75)\end{array}$ & $\begin{array}{l}53 \% \quad \mathrm{p}=0.56 \\
64 \%\end{array}$ & $\begin{array}{ll}41 \% & \mathrm{p}=0.71 \\
52 \% & \end{array}$ & $\begin{array}{l}59 \% \mathrm{p}=0.34 \\
71 \%\end{array}$ \\
\hline $\begin{array}{l}\text { ECOG }=0(n=40) \\
\operatorname{ECOG}=1(n=52)\end{array}$ & $\begin{array}{l}68 \% \mathrm{p}=0.40 \\
58 \%\end{array}$ & $\begin{array}{l}55 \% \mathrm{p}=0.38 \\
46 \%\end{array}$ & $\begin{array}{ll}73 \% & p=0.47 \\
65 \% & \end{array}$ \\
\hline
\end{tabular}

Table 3: Univariate analysis for prognostic variables associated with time to metastatic disease or death

\begin{tabular}{|c|c|c|c|c|c|}
\cline { 3 - 6 } \multicolumn{1}{c|}{} & \multicolumn{2}{c|}{ Univariable Results } & \multicolumn{2}{c|}{ Multivariable Results } \\
\hline Variable & Comparison* & $\begin{array}{c}\text { Hazard Ratio } \\
(\mathbf{9 5 \%} \text { CI })\end{array}$ & p-value & $\begin{array}{c}\text { Hazard Ratio } \\
(\mathbf{9 5 \%} \text { CI) }\end{array}$ & p-value \\
\hline Age & $<65$ vs. $\geq 65$ years old & $1.00(0.96,1.04)$ & 0.9678 & & \\
\hline Gender & Female vs Male & $0.97(0.46,2.04)$ & 0.9401 & & \\
\hline
\end{tabular}




\begin{tabular}{|c|c|c|c|c|c|}
\hline \multirow[b]{2}{*}{ Variable } & \multirow[b]{2}{*}{ Comparison* } & \multicolumn{2}{|c|}{ Univariable Results } & \multicolumn{2}{|c|}{ Multivariable Results } \\
\hline & & $\begin{array}{l}\text { Hazard Ratio } \\
\qquad(95 \% \mathrm{CI})\end{array}$ & p-value & $\begin{array}{c}\text { Hazard Ratio } \\
\qquad(95 \% \text { CI })\end{array}$ & p-value \\
\hline Stage & IIIB vs IIIA & $1.79(0.91,3.52)$ & 0.0922 & $2.87(1.21,6.81)$ & 0.0165 \\
\hline Histology & $\begin{array}{l}\text { non-squamous vs } \\
\text { squamous }\end{array}$ & $0.57(0.29,1.12)$ & 0.0999 & $0.63(0.30,1.32)$ & 0.2192 \\
\hline \multirow[t]{3}{*}{ Smoking status } & Current vs Former & $1.39(0.62,3.10)$ & 0.7204 & & \\
\hline & Current vs Never & $1.21(0.25,5.74)$ & & & \\
\hline & Former vs Never & $0.87(0.20,3.71)$ & & & \\
\hline PDL-1 status & Negative vs Positive & $0.50(0.12,2.16)$ & 0.3505 & & \\
\hline $\begin{array}{l}\text { Any adverse } \\
\text { event }\end{array}$ & Grade $<=2$ vs Grade $>=3$ & $0.65(0.33,1.29)$ & 0.2194 & & \\
\hline $\begin{array}{l}\text { Pneumonitis } \\
\text { grade }\end{array}$ & Grade $<=2$ vs Grade $>=3$ & $0.57(0.17,1.86)$ & 0.3493 & & \\
\hline $\begin{array}{l}\text { Duration of } \\
\text { treatment with } \\
\text { pembrolizumab }\end{array}$ & $\begin{array}{c}<4 \text { cycles vs }>=4 \text { cycles of } \\
\text { treatment }\end{array}$ & $5.98(2.75,13.00)$ & $<.0001$ & $9.14(3.35,24.92)$ & $<.0001$ \\
\hline Type of chemo & $\begin{array}{l}\text { Carboplatin/Paclitaxel vs } \\
\text { Cisplatin/Etoposide }\end{array}$ & $1.36(0.61,3.03)$ & 0.4462 & & \\
\hline ECOG & 0 vs 1 & $0.63(0.31,1.29)$ & 0.2035 & & \\
\hline \begin{tabular}{|l|} 
Time between \\
radiation to \\
pembrolizumab
\end{tabular} & 4-6 weeks vs 6-8 weeks & $1.40(0.61,3.24)$ & 0.4315 & & \\
\hline V20 & $<=20 \%$ vs $>20 \%$ & $0.38(0.13,1.09)$ & 0.0716 & $0.64(0.21,1.95)$ & 0.4346 \\
\hline
\end{tabular}

*reference category is the second category

Table 4: Univariate analysis for prognostic variables associated with progression-free survival

\begin{tabular}{|c|c|c|c|c|c|}
\cline { 3 - 6 } \multicolumn{1}{c|}{} & \multicolumn{3}{c|}{ Univariable Results } & \multicolumn{2}{c|}{ Multivariable Results } \\
\hline Variable & Comparison* & $\begin{array}{c}\text { Hazard Ratio } \\
(\mathbf{9 5 \%} \text { CI })\end{array}$ & $\begin{array}{c}\text { p-value } \\
\text { Hazard Ratio } \\
(\mathbf{9 5 \%} \text { CI) }\end{array}$ & p-value \\
\hline Age & $<65$ vs. $\geq 65$ years old & $1.00(0.97,1.04)$ & 0.8557 & & \\
\hline Gender & Female vs Male & $0.80(0.41,1.55)$ & 0.5065 & & \\
\hline Stage & IIIB vs IIIA & $1.56(0.86,2.83)$ & 0.1444 & & \\
\hline
\end{tabular}




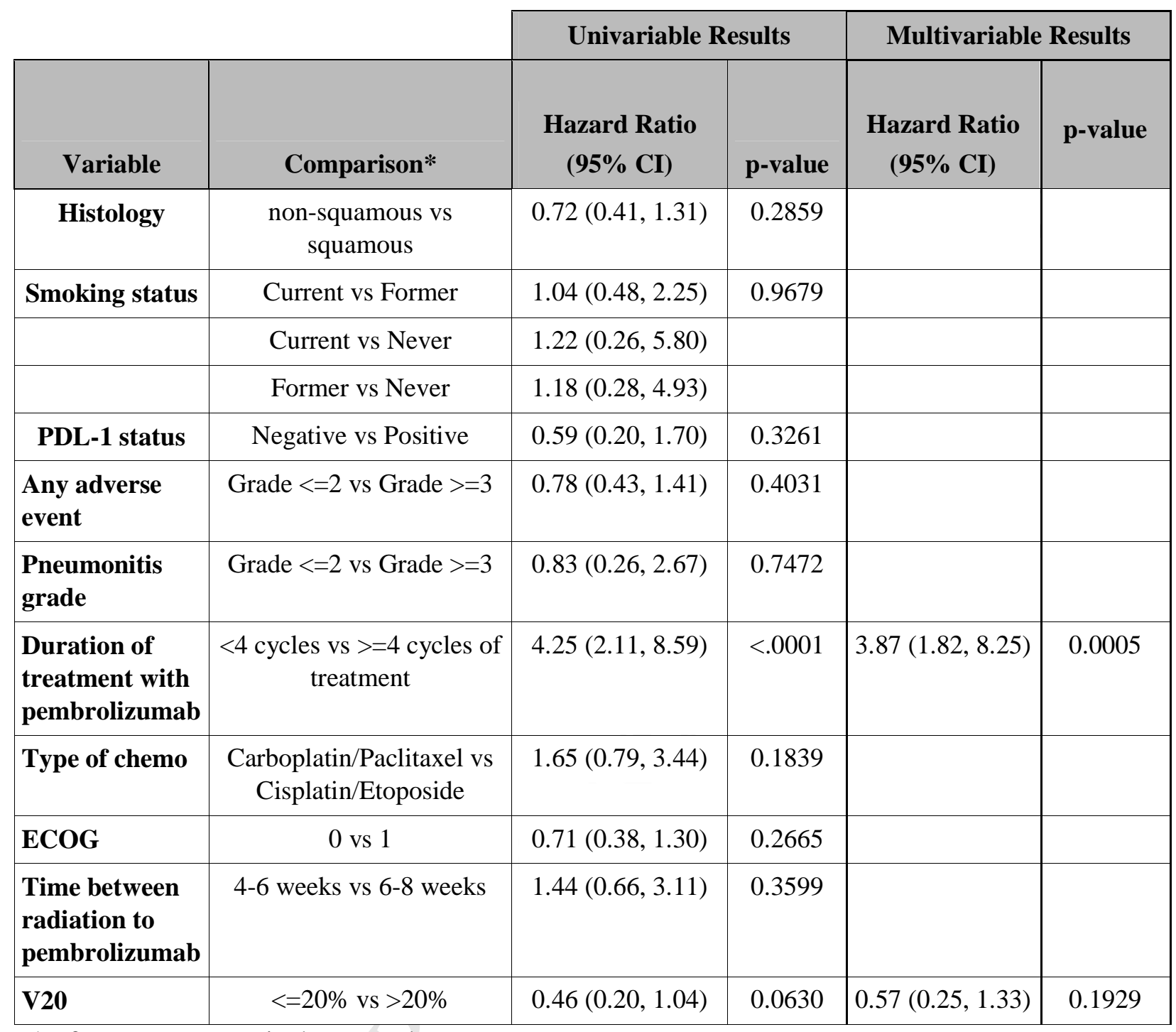

*reference category is the second category

Table 5: Univariate analysis for prognostic variables associated with overall survival

\begin{tabular}{|c|c|c|c|c|c|}
\cline { 3 - 5 } \multicolumn{2}{c|}{} & \multicolumn{2}{c|}{ Univariable Results } & \multicolumn{2}{c|}{ Multivariable Results } \\
\hline Variable & Comparison* & $\begin{array}{c}\text { Hazard Ratio } \\
(\mathbf{9 5 \%} \text { CI) }\end{array}$ & p-value & $\begin{array}{c}\text { Hazard Ratio } \\
(\mathbf{9 5 \%} \text { CI) }\end{array}$ & p-value \\
\cline { 1 - 5 } Age & $<65$ vs. $\geq 65$ years old & $1.01(0.96,1.05)$ & 0.7975 & & \\
\hline Gender & Female vs Male & $0.84(0.38,1.85)$ & 0.6634 & & \\
\hline Stage & IIIB vs IIIA & $1.69(0.81,3.52)$ & 0.1588 & & \\
\hline Histology & non-squamous vs squamous & $0.52(0.25,1.09)$ & 0.0829 & $0.64(0.30,1.35)$ & 0.2390 \\
\hline
\end{tabular}




\begin{tabular}{|c|c|c|c|c|c|}
\hline \multirow[b]{2}{*}{ Variable } & \multirow[b]{2}{*}{ Comparison* } & \multicolumn{2}{|c|}{ Univariable Results } & \multicolumn{2}{|c|}{ Multivariable Results } \\
\hline & & $\begin{array}{l}\text { Hazard Ratio } \\
\text { (95\% CI })\end{array}$ & p-value & $\begin{array}{l}\text { Hazard Ratio } \\
\text { (95\% CI })\end{array}$ & p-value \\
\hline \multirow[t]{3}{*}{ Smoking status } & Current vs Former & $1.55(0.66,3.67)$ & 0.6043 & & \\
\hline & Current vs Never & $1.48(0.31,7.18)$ & & & \\
\hline & Former vs Never & $0.95(0.22,4.11)$ & & & \\
\hline PDL-1 status & Negative vs Positive & $0.26(0.03,1.96)$ & 0.1901 & & \\
\hline $\begin{array}{c}\text { Any adverse } \\
\text { event }\end{array}$ & Grade $<=2$ vs Grade $>=3$ & $0.55(0.26,1.17)$ & 0.1208 & & \\
\hline \begin{tabular}{|l} 
Pneumonitis \\
grade
\end{tabular} & Grade $<=2$ vs Grade $>=3$ & $0.37(0.11,1.23)$ & 0.1034 & & \\
\hline \begin{tabular}{|l|}
$\begin{array}{l}\text { Duration of } \\
\text { treatment with } \\
\text { pembrolizumab }\end{array}$ \\
\end{tabular} & $\begin{array}{c}<4 \text { cycles vs }>=4 \text { cycles of } \\
\text { treatment }\end{array}$ & $5.40(2.43,12.02)$ & $<.0001$ & $4.91(2.18,11.06)$ & 0.0001 \\
\hline Type of chemo & $\begin{array}{c}\text { Carboplatin/Paclitaxel vs } \\
\text { Cisplatin/Etoposide }\end{array}$ & $1.58(0.64,3.90)$ & 0.3225 & & \\
\hline ECOG & 0 vs 1 & $0.71(0.33,1.54)$ & 0.3862 & & \\
\hline \begin{tabular}{|l|}
$\begin{array}{l}\text { Time between } \\
\text { radiation to } \\
\text { pembrolizumab }\end{array}$ \\
\end{tabular} & 4-6 weeks vs $6-8$ weeks & $1.54(0.65,3.63)$ & 0.3225 & & \\
\hline V20 & $<=20 \%$ vs $>20 \%$ & $0.51(0.17,1.48)$ & 0.2136 & & \\
\hline
\end{tabular}

*reference category is the second categor 


\section{Discussion:}

Prognostic variables associated with better or worse outcomes for patients with stage III NSCLC treated with concurrent chemoradiation are well characterized ${ }^{7}$. However, prognostic variables associated with outcomes are not well defined in this patient population receiving consolidation PD-1 or PD-L1 inhibition. The analysis performed from HCRN LUN 14-179 reported here indicates that receiving 4 or more cycles of consolidation pembrolizumab is associated with improved PFS, TMDD, and OS compared with receiving fewer than 4 cycles. The interpretation of this, however, should be undertaken with caution. It is possible (and even likely) that this simply represents a patient population who tolerated therapy well and may have had more favorable tumor biology. It should be noted, though, that duration of pembrolizumab therapy remained prognostic when factoring in other variables, including stage, PD-L1 score, histology, V20, and PS, which can influence efficacy outcomes. The optimal duration of consolidation PD-1 or PD-L1 inhibition after chemoradiation is not defined. The PACIFIC trial and the HCRN LUN 14-179 trials each permitted up to 1 year of consolidation checkpoint inhibition. Approximately $40 \%$ of patients on each study were able to receive 1 year of therapy, and the median duration of consolidation therapy received in both studies was approximately 9 months 5 .

Other known prognostic variables for patients with stage III NSCLC were evaluated in the current study. V20 $<20 \%$ is associated with less toxicity and better outcomes for patients treated with chemoradiation for stage III NSCLC ${ }^{10}$. Based upon the current analysis, it appears that V20 $<20 \%$ is also associated with improved PFS and TMDD with consolidation pembrolizumab. Lower V20 may simply be a surrogate for lower volume of disease, selecting out patients who may be more curable. Furthermore, non-squamous NSCLC was also associated with improved survival with consolidation pembrolizumab.

Subset analyses from the PACIFIC trial suggested that patients with PD-L1 expression of $<1 \%$ may not have improved survival with consolidation durvalumab compared with placebo, although PFS was improved with durvalumab in that analysis ${ }^{5}$. The HCRN LUN 14-179 trial utilized a PD-L1 testing platform that assessed PD-L1 expression in tumor cells along with other cells in the microenvironment. Utilizing this assay, PD-L1 expression of $<1 \%$ was not associated with inferior survival with consolidation pembrolizumab. It is possible that the 
utilization of different assays resulted in disparate results between HCRN LUN 14-179 and the PACIFIC trial. The optimal therapy for patients with PD-L1 scores of $1 \%$ remains undefined.

In addition, a subset analysis from the PACIFIC trial suggested that initiating consolidation durvalumab within 2 weeks of completing chemoradiation was associated with improved outcomes 5 . In contrast, patients enrolled onto HCRN LUN 14-179 were required to wait a minimum of 4 weeks and a maximum of 8 weeks after completing chemoradiation prior to initiating pembrolizumab. The current study evaluated the differences in outcomes of patients initiating pembrolizumab 4-6 weeks after chemoradiation versus those initiating pembrolizumab 6-8 weeks after chemoradiation. No difference was detected in efficacy outcomes (PFS, TMDD, OS) between these subgroups. It is possible that patients receiving durvalumab within 2 weeks of chemoradiation on the PACIFIC trial represented patients with fewer medical problems, improved tolerance to therapy, and better performance status. Furthermore, smoking status, age, gender, chemotherapy regimen, and development of pneumonitis during consolidation immunotherapy do not appear to be associated with outcomes in this patient population.

While this was the first attempt to evaluate prognostic variables utilizing immunotherapy after chemoradiation for patients with stage III NSCLC, it is important to recognize the limitations of this analysis. This analysis was retrospective and unplanned. Secondly, a p value of $<1 \%$ was utilized as a cut-off for utilization in the multivariate model. Third, the sample size of this study is relatively small. Fourth, the PD-L1 assay utilized is not standard. Fifth, PFS can be challenging to define in a patient population treated with radiation due to the difficulty of interpreting local progression. Nevertheless, despite these significant limitations, this study serves as hypothesis generating to test variables in larger studies of this patient population..

In conclusion, this is the first dedicated report assessing prognostic variables associated with outcomes in patients with stage III NSCLC treated with chemoradiation followed by consolidation pembrolizumab. Efforts are underway to build off the success of the PACIFIC and HCRN LUN 14-179 trials. Given the increased risks and costs associated with consolidation immunotherapy in this setting, it is essential to define the optimal duration of immunotherapy and to identify prognostic markers associated with benefit (or detriment) with this strategy. One such effort is underway through the BIG10 Cancer Research Consortium (NCT03285321) which 
will evaluate multiple clinical factors, radiation treatment variables, and molecular biomarkers associated with outcomes in patients treated with consolidation immunotherapy strategies. 


\section{References:}

1. National Cancer Institute NC. Non-Small Cell Lung Cancer Treatment. Available at https://www.cancer.gov/types/lung/hp/non-small-cell-lung-treatment-pdq\#section/_4889. 2018.

2. Albain KS, Crowley JJ, III ATT, et al. Concurrent Cisplatin, Etoposide, and Chest Radiotherapy in Pathologic Stage IIIB Non-Small-Cell Lung Cancer: A Southwest Oncology Group Phase II Study, SWOG 9019. Journal of Clinical Oncology 2002;20:3454-3460.

3. Albain KS, Rusch VW, Crowley JJ, et al. Concurrent cisplatin/etoposide plus chest radiotherapy followed by surgery for stages IIIA (N2) and IIIB non-small-cell lung cancer: mature results of Southwest Oncology Group phase II study 8805. Journal of Clinical Oncology 1995;13:1880-1892.

4. (NCCN) NCCN. NCCN Clinical practice guidelines in oncology. Available at https://www.nccn.org/professionals/physician_gls/pdf/aml.pdf Accessed February 202019.

5. Antonia SJ, Villegas A, Daniel D, et al. Durvalumab after chemoradiotherapy in stage III nonsmall-cell lung cancer. New England Journal of Medicine 2017;377:1919-1929.

6. Berghmans T, Paesmans M, Sculier JP. Prognostic factors in stage III non-small cell lung cancer: a review of conventional, metabolic and new biological variables. Therapeutic advances in medical oncology 2011;3:127-138.

7. Urvay SE, Yucel B, Erdis E, et al. Prognostic Factors in Stage III Non-Small-Cell Lung Cancer Patients. Asian Pacific journal of cancer prevention : APJCP 2016;17:4693-4697.

8. Sloan JA, Zhao X, Novotny PJ, et al. Relationship between deficits in overall quality of life and non-small-cell lung cancer survival. J Clin Oncol 2012;30:1498-1504.

9. Durm GA, Althouse SK, Sadiq AA, et al. Phase II trial of concurrent chemoradiation with consolidation pembrolizumab in patients with unresectable stage III non-small cell lung cancer: Hoosier Cancer Research Network LUN 14-179. Journal of Clinical Oncology 2018;36:8500-8500.

10. Ramella S, Trodella L, Mineo TC, et al. Adding ipsilateral V20 and V30 to conventional dosimetric constraints predicts radiation pneumonitis in stage IIIA-B NSCLC treated with combinedmodality therapy. International Journal of Radiation Oncology* Biology* Physics 2010;76:110-115. 